[Case Report]

\title{
A Case of Non-hereditary White Sponge Nevus in the Oral Cavity Successfully Treated with Tetracycline Ointment and Oral Multivitamins
}

\author{
Toshiyuki Akimori ${ }^{*}$, Daisuke Ueda, Mayuko Takada, Kousei Kabata, Sakiho Fukui and Akihiko Miyawaki \\ Department of Dentistry and Oral Surgery, University Hospital of Occupational and Environmental Health, Japan. \\ Yahatanishi-ku, Kitakyushu 807-8556, Japan
}

\begin{abstract}
White spongiform nevus is an autosomal dominant inherited disorder first reported by Cannon in 1935. It is a rare disease in which the oral mucosa thickens into an edematous and spongy state and is often accompanied by difficult to recognize subjective symptoms. We report a case of multiple non-hereditary white cavernous nevi in the oral mucosa. The subject was a 22-year-old man with a chief complaint of white lesions in his oral cavity. Examination revealed thick edematous and sponge-like white lesions on the bilateral buccal mucosa, upper and lower lip mucosa, and bilateral lingual margins. There was no history of similar lesions in his family or among his relatives. We diagnosed the case as non-hereditary white sponge nevus, based on clinical and histopathological findings. Although difficult to treat, the lesions disappeared with tetracycline ointment application and oral intake of multiple vitamin supplements. No recurrence of the lesion was observed thereafter.
\end{abstract}

Keywords : white sponge nevus, oral mucosa, non-hereditary.

(Received August 20, 2021, accepted August 31, 2021)

\section{Introduction}

A white sponge nevus (WSN) is a white lesion that occurs in the mucous membranes of the oral cavity, nasal cavity, esophagus, rectum, vagina, and anus. It is considered an autosomal dominant genetic disorder, first reported by Cannon in 1935 [1], and sporadic cases have been reported [2,3]. Herein, we report a case of non-hereditary WSN that we experienced difficulty in treating. The lesion subsided following tetracycline ointment application and vitamin administration, thus we report an overview.

\section{Case}

The patient was a 22-year-old man who visited the hospital with a complaint of a rough oral cavity. He had a medical history of epilepsy but no family history of similar symptoms. He had been aware of the rough feeling in the oral cavity since he was 17 years old, but had ignored it because there was no pain. He recently noticed an enlargement and roughening of these white spots and was referred to our department for medical treatment. Upon physical examination, there were no particular abnormalities in the extraoral findings, but intraoral findings showed painless, thickened, spongelike white lesions on the upper and lower lips, bilateral buccal mucosa, and bilateral tongue margins. The surface of the lesion was rough, whereas ablation of the epithelium was observed when scraped (Figure 1 A-D).

The clinical diagnosis was oral lichen planus, but

\footnotetext{
*Corresponding Author: Toshiyuki AKıмoRI, Department of Dentistry and Oral Surgery, University Hospital of Occupational and Environmental Health, Japan. 1-1-1 Iseigaoka, Yahatanishi-ku, Kitakyushu 807-8556, Japan, Tel:+81-93-603-1611, Fax:+81-93-603-4639, E-mail:8het-perico@ clnc.uoeh-u.ac.jp
} 

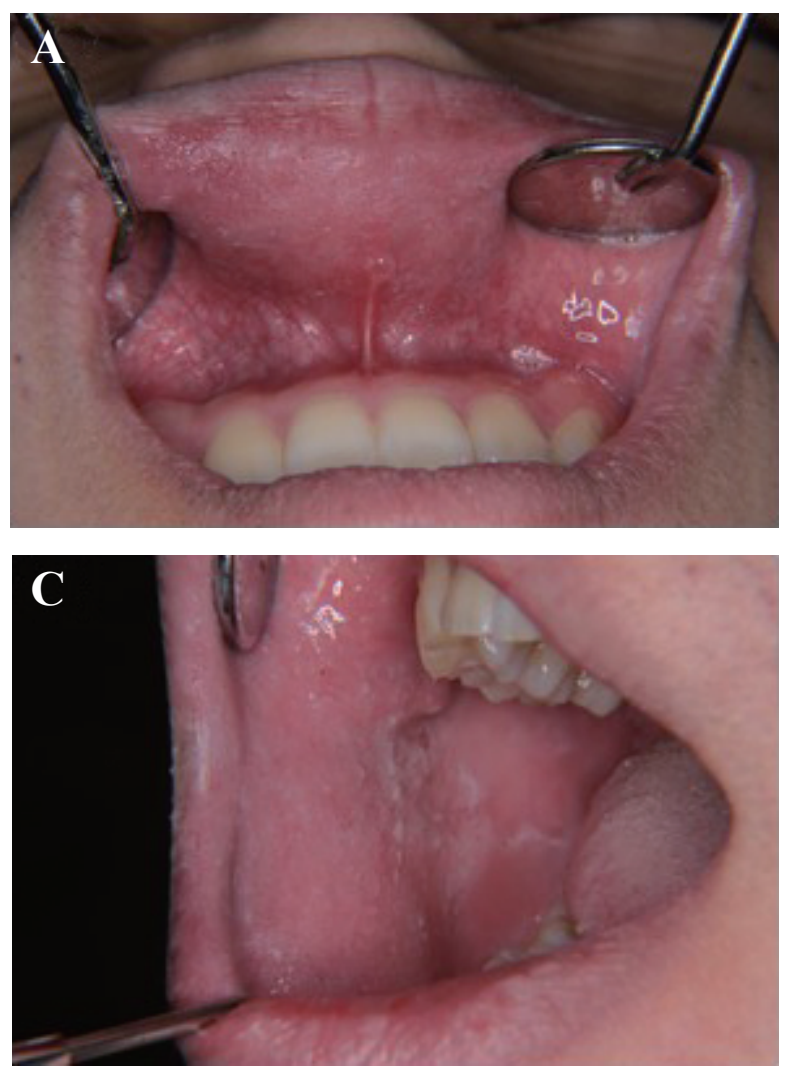
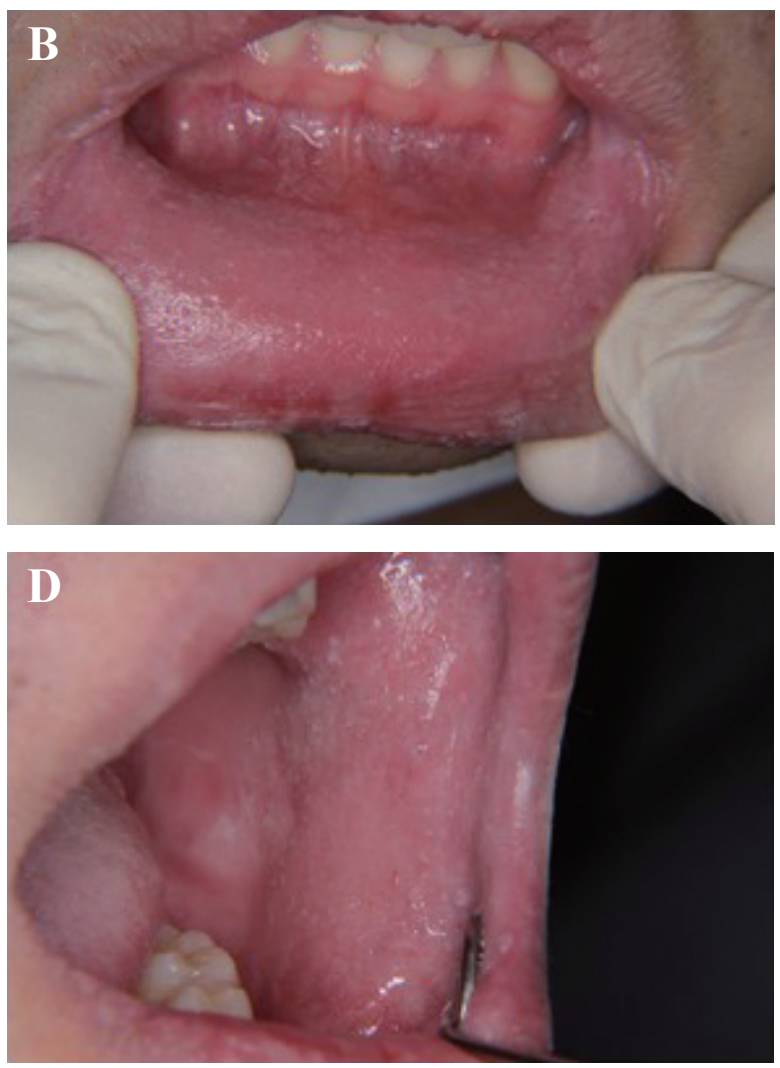

Figure 1. Photographs of the lesion at the initial examination. A: Upper lingual mucosa. B: Lower lingual mucosa. C: Right buccal mucosa. D: Left buccal mucosa. Spongy, thickened and whitish lesions were noted. Their surfaces appeared rough.

oral candidiasis was also suspected at the initial visit. A bacterial culture test of candidiasis was performed, but the procedure and course were negative. Subsequently, oral lichen planus was suspected; thus, a steroid ointment was applied for approximately two weeks, after which the lesion expanded. A biopsy of the right buccal mucosa was then performed. Azithromycin was prescribed to prevent post-biopsy infection; consequently, the lesion temporarily reduced. The biopsy results revealed a WSN with a bacterial mass adhering to its mucosal surface. Non-hereditary WSN was diagnosed because no similar lesions were found in his family. As this disease may develop in areas other than the oral cavity, a systemic examination was recommended, but his consent was not obtained. A tetracycline ointment was applied for about one month, but the lesions only shrank without fully disappearing. The lesion resolved approximately two weeks after the oral administration of over-the-counter multivitamins was initiated. The lesion recurred approximately one month after the tetracycline ointment was discontinued and only oral multivitamins were taken. The lesion resolved completely with the combined use of the tetracycline ointment and multivitamin preparation for six months (Figure 2A-D), and no subsequent recurrences were observed.

Histopathology revealed a thickened stratified squamous epithelium exhibiting parakeratosis, with concentrated nuclei and a swollen cytoplasm. Some hollowed-out cells had an acidophilic cytoplasmic border around the nucleus (Figure 3A, B); therefore, the diagnosis was WSN.

\section{Discussion}

A white sponge nevus (WSN) was first reported in 1909 by Hyde as an unusual nevus on the tongue of a five-year-old boy [4]. In 1935, Cannon named it "WSN [1]." Clinically, it has a white appearance, edematous mucosa, and spongy surface. It is characteristic for these lesions to have a part of the epithelium exfoliated when the mucous membrane is rubbed. It was thought 

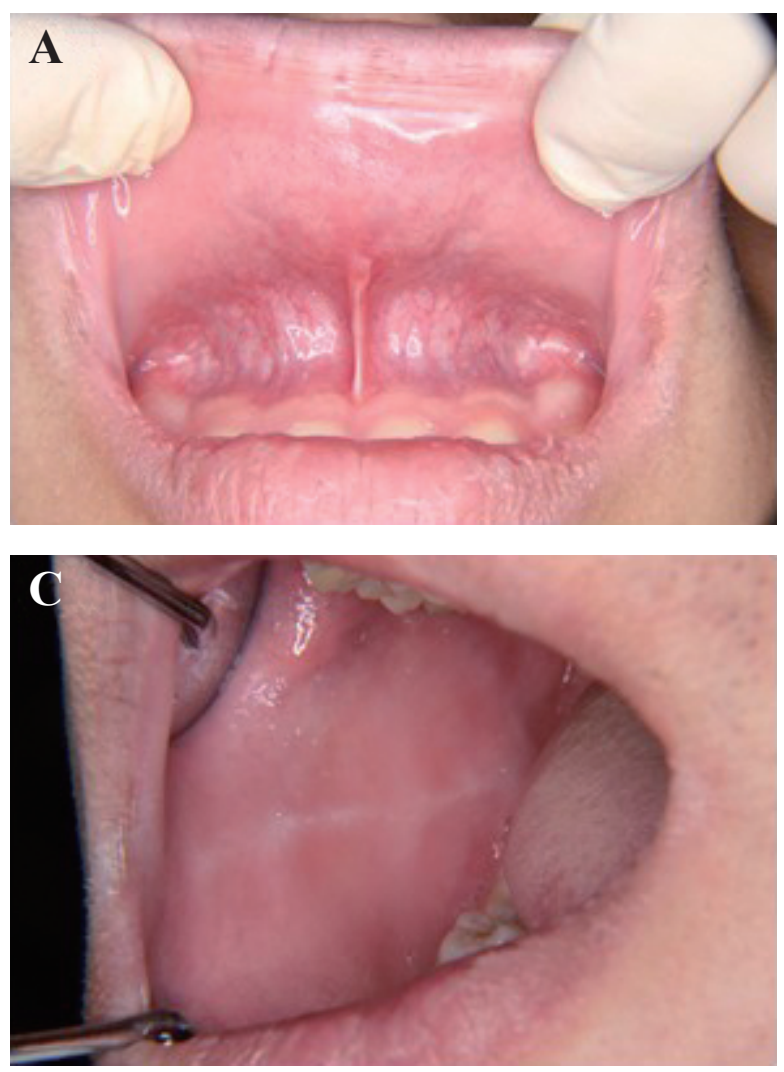

Figure 2. Post-treatment intraoral image. A: Upper lingual mucosa. B: Lower lingual mucosa. C: Right buccal mucosa. D: Left buccal mucosa. The lesions disappeared completely.
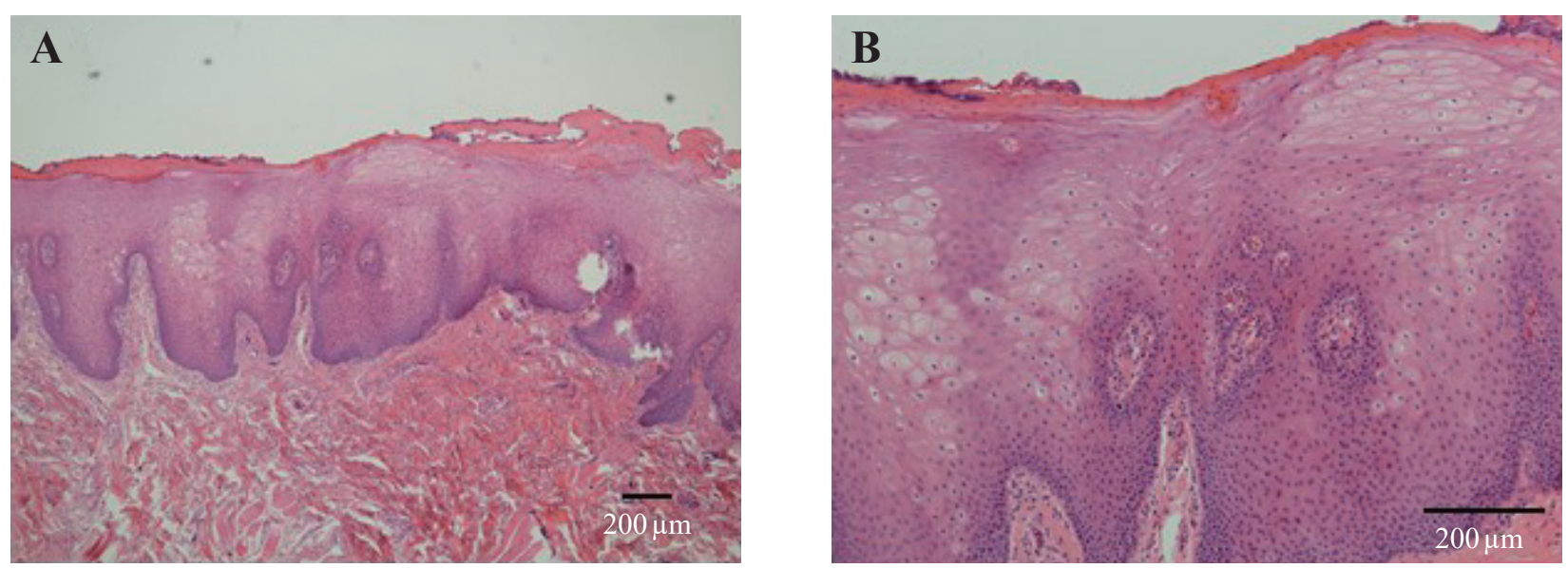

Figure 3. Histopathological findings. A: Low power view microphotograph; the epithelium shows parakeratosis and thickening due to edema and vacuolization of the spinous layer. There is no change in the basal cell layer. B: High power view microphotograph showing that enlarged prickle cells are vacuolated in the cytoplasm.

to be an autosomal-dominant disease, but its occurrence may be irregular and non-hereditary $[3,5]$. It was previously theorized that human papilloma virus, bacterial [6], or fungal infections [7] were the causes of these outbreaks, but mutations in cytokeratin 4 or 13 have been reported recently [8].
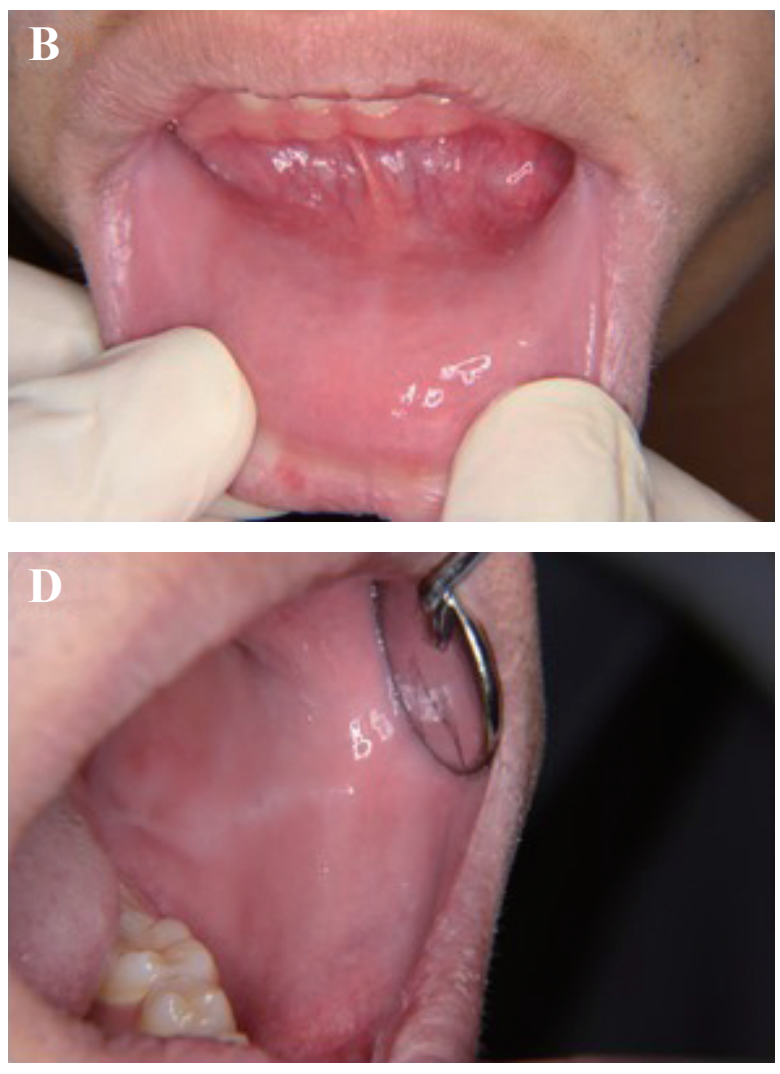
test was not obtained in our case, we could not confirm any occurrence at other sites. Differentiating diseases includesorallichenplanus, leukoplakia, oralcandidiasis, oral symptoms of congenital onycholysis, and hereditary benign intraepithelial dyskeratosis [11]. In our case, oral candidiasis was excluded following a bacterial culture. Oral lichen planus was also ruled out because the lesions enlarged on applying a steroid ointment. WSN was diagnosed based on the histopathological and characteristic clinical findings, wherein a part of the surface layer exfoliated after being scraped and revealed a thickened sponge-like white lesion.

We were able to identify 28 cases of WSN in Japan that occurred in the oral cavity, including our report, of which 13 were non-hereditary (Table 1). The average age of these patients was 29.8 years, ranging from 12 to 51 years; no gender difference was noted. All cases occurred in the buccal mucosa. Only two cases described a treatment method: the lesion subsided on the oral administration of a macrolide antibacterial drug in one case and of etretinate in the other (Table 1).

Our case involved a 22-year-old man who also had lesions on the bilateral buccal mucosa and had the subjective symptom of a rough sensation in the oral cavity. He visited a medical institution relatively early and also showed a temporary reduction of lesions with azithromycin, which was prescribed to prevent postbiopsy infections. Bacterial infections may be considered to cause this disease, and macrolide antibacterial agents are effective, as reported in previous cases, but the current predominant theory is that this disease is caused by a mutation in the keratin gene, and bacterial infection cannot be identified as the main cause. Frequent antibiotic administration should be avoided to reduce the emergence of resistant strains. In our case, histopathological examination revealed the adhesion of a bacterial mass on the surface layer of the mucosa; therefore, we chose to topically apply a tetracycline ointment instead of an ingestible antibacterial drug. Long-term steroid ointments have been reported to cause malignant transformation of these lesions [15], and our patient's lesion expanded when steroid ointment was used for approximately two weeks. Thus, the careless use of steroid ointments

Table 1. Non-hereditary WSN occurring in the oral mucosa in Japan

\begin{tabular}{|c|c|c|c|c|c|c|}
\hline Authors & Case & Age & Sex & Location & Treatment & Final outcome \\
\hline Suzuki K et al [13] & 1 & 20 & $\mathrm{~F}$ & $\begin{array}{l}\text { buccal mucosa, dorsum and under of } \\
\text { tongue, and lower gingiva }\end{array}$ & $\begin{array}{l}\text { penicillin } \cdot \\
\text { multivitamins } \cdot \text { steroids }\end{array}$ & no change \\
\hline Ohgo N et al [9] & 2 & 16 & $\mathrm{~F}$ & $\begin{array}{l}\text { buccal mucosa, lingual mucosa, and } \\
\text { dorsum of tongue }\end{array}$ & etretinate & improvement \\
\hline Jinbu Y et al [11] & 3 & 30 & M & $\begin{array}{l}\text { buccal mucosa and lower lingual } \\
\text { mucosa }\end{array}$ & macrolide & disappearance \\
\hline Inoue $\mathrm{R}$ et al [12] & 4 & 48 & $\mathrm{~F}$ & buccal mucosa and lingual mucosa & observation & no change \\
\hline Tsukamoto $\mathrm{H}$ et al [6] & 5 & 44 & M & buccal mucosa and lingual mucosa & tetracycline & $\begin{array}{l}\text { repeat recurrent } \\
\text { and improvement }\end{array}$ \\
\hline Shibuya T et al [10] & 6 & 12 & $\mathrm{~F}$ & $\begin{array}{l}\text { buccal mucosa and lower lingual } \\
\text { mucosa }\end{array}$ & macrolide & disappearance \\
\hline Yamamoto A et al [8] & 7 & 20 & M & left buccal mucosa & NL & NL \\
\hline Yamamoto A et al [8] & 8 & 36 & $\mathrm{~F}$ & buccal mucosa & NL & NL \\
\hline Yamamoto A et al [8] & 9 & 24 & $\mathrm{~F}$ & $\begin{array}{l}\text { buccal mucosa and lower lingual } \\
\text { mucosa }\end{array}$ & NL & NL \\
\hline Yamamoto A et al [8] & 10 & 30 & M & $\begin{array}{l}\text { buccal mucosa and lower lingual } \\
\text { mucosa }\end{array}$ & NL & NL \\
\hline Yamamoto A et al [8] & 11 & 35 & $\mathrm{~F}$ & buccal mucosa and edge of tongue & NL & NL \\
\hline Yamamoto A et al [8] & 12 & 51 & $\mathrm{~F}$ & $\begin{array}{l}\text { buccal mucosa and lower lingual } \\
\text { mucosa }\end{array}$ & NL & NL \\
\hline Present case & 13 & 22 & M & $\begin{array}{l}\text { buccal mucosa, lingual mucosa and } \\
\text { edge of tongue }\end{array}$ & $\begin{array}{l}\text { tetracycline oitment } \\
\text { multivitamins }\end{array}$ & disappearance \\
\hline
\end{tabular}

WSN: A white spouge nevus, F: female, M: male, NL: not listed 
should be avoided.

Etretinate, which has an inhibitory effect on hyperkeratinization, has previously been considered to treat WSN effectively because the etiology of this disease is the abnormal keratinization of the oral mucosa, but its effectiveness is currently considered controversial [7, 16], and its indication is considered difficult considering the potential side effects such as teratogenicity. For our patient, we chose a multivitamin treatment course composed of the water-soluble vitamins B1, B2, B6, niacin, and pantothenic acid. Vitamin B2 is believed to be associated with the maintenance of mucosal function. Vitamin B2-deficiency may lead to dermatitis, cheilitis, and angular cheilitis [16]. As water-soluble vitamins are not easily accumulated in the body and are easily excreted, they do not cause other illnesses and are relatively safe to use.

No cure has been established for this case, but applying tetracycline ointment and ingesting multivitamins were considered safer than other previously reported methods and should be attempted as a treatment method.

\section{Conflict of Interest}

The authors declare that they have no conflict of interest.

\section{References}

1. Cannon AB (1935): White sponge nevus of the mucosa (naevus spongiosus albus mucosae). Archives of Dermatology and Syphilology 31 (3): 365-370

2. Witkop CJ, Jr. \& Gorlin RJ (1961): Four hereditary mucosal syndromes: comparative histology and exfoliative cytology of Darier-White's disease, hereditary benign intraepithelial dyskeratosis, white sponge nevus, and pachyonychia congenita. Arch Dermatol 84: 762-771

3. Lucchese A \& Favia G (2006): White sponge naevus with minimal clinical and histological changes: report of three cases. Journal of Oral Pathology \& Medicine 35 (5): 317-319

4. Hyde JN (1909): An unusual naevus of the tongue in a five-year-old boy. J Cutan Dis 27: 256

5. Isome H, Matsuno T, Matsumoto T, Imai S \& Iwashige Y (2019): A case and familial cases of white sponge nevus successfully treated by long term-low dose macrolide therapy. Japanese Journal of Oral and Maxillofacial Surgery 65 (12): 786-791 (in Japanese)

6. Tsukamoto H, Yoshizawa Y, Nagumo T, Shirota T, Hatori M \& Shintani S (2011): Two cases of white sponge nevus of the buccal mucosa. Japanese Journal of Oral and Maxillofacial Surgery 57 (11): 582-586 (in Japanese)

7. Lim J \& Ng SK (1992): Oral tetracycline rinse improves symptoms of white sponge nevus. Journal of the American Academy of Dermatology 26 (6): 10031005

8. Yamamoto A, Jinbu Y, Kashiwazaki A, Mori Y, Komine M \& Demitsu T (2020): Immunohistochemical Study of Cytokeratin Expression in Familial and Nonfamilial White Sponge Nevi. Journal of Japanese Society of Oral Medicine 26 (1): 16-21 (in Japanese)

9. Ohgo N \& Hiraki S (1998): White sponge nevus. Pract. Dermatol 20(7): 604-606 (in Japanese)

10. Shibuya T, Shimamura C, Hashimoto M, Honma M, Yamamoto A \& Iizuka H (2012): A case of white sponge nevus. Japanese Journal of Clinical Dermatology 66: 325-327 (in Japanese)

11. Jinbu Y, Tsukinoki K, Hori M, Aoki M, Kusama M \& Watanabe Y (2004): A Case of White Sponge Nevuslike Lesion of the Oral Mucosa Successfully Treated with Azithromycin. Oral Medicine \& Pathology 9 (1): 35-37

12. Inoue R, Nishizawa A, Takayama K, Satoh T \& Yokozeki H (2009) : White sponge nevus - Suspected case of lichen planus - . Pract. Dermatol 31(2): 195198 (in Japanese)

13. Suzuki K, Iwama H, Yoshida H, Yamaguchi K \& Fukuda $H$ (1996): A case of white sponge nevus in the oral cavity. JAPANESE JOURNAL OF ORAL AND MAXILLOFACIAL SURGERY 42 (3): 308-310 (in Japanese)

14. Morita S, Maruoka Y, Fukada K, Ando T \& Ogiuchi H (2006): A Case of White Spongy Nevus that Developed in the Buccal Mucosa. Journal of Japanese Society for Oral Mucous Membrane 12 (2): 71-75 (in Japanese)

15. Downham II TF \& Plezia RA (1978): Oral SquamousCell Carcinoma within a White-Sponge Nevus. The Journal of Dermatologic Surgery and Oncology 4 (6): $470-472$

16. Japan meat information service center (2013): Water-solu- 
ble vitamins. http://www.jmi.or.jp/qanda/bunrui5/q_081.

html (Accessed July 2, 2021) (in Japanese)

J UOEH $43(4): 421-426(2021)$ 